\title{
Identification and characterization of an anti-oxidative stress-associated mutant of Aspergillus fumigatus transformed by Agrobacterium tumefaciens
}

\author{
ZHONGQI FAN ${ }^{1,2}$, HUIMEI YU ${ }^{1}$, QI GUO ${ }^{1,3}$, DAN HE ${ }^{1}$, BAIJI XUE ${ }^{1}$, \\ XIANGLI XIE $^{1}$, KOJI YOKOYAMA ${ }^{4}$ and LI WANG $^{1}$ \\ ${ }^{1}$ Department of Pathogenobiology, Jilin University Mycology Research Center,
}

Key Laboratory of Pathobiology, Ministry of Education, College of Basic Medical Sciences, Jilin University;

${ }^{2}$ Department of Hepatobiliary and Pancreatic Surgery, The First Hospital of Jilin University, Changchun, Jilin 130021;

${ }^{3}$ Department of Hand Surgery, China-Japan Union Hospital of Jilin University, Changchun, Jilin 130031, P.R. China;

${ }^{4}$ Medical Mycology Research Center, Chiba University, Chiba 260-8673, Japan

Received January 23, 2015; Accepted October 29, 2015

DOI: $10.3892 / \mathrm{mmr} .2016 .4839$

\begin{abstract}
Aspergillus fumigatus is one of the most common opportunistic pathogenic fungi, surviving in various environmental conditions. Maintenance of the redox homeostasis of the fungus relies upon the well-organized regulation between reactive oxygen species generated by immune cells or its own organelles, and the activated anti-oxidative stress mechanism. To investigate such a mechanism, the present study obtained a number of randomly-inserted mutants of A. fumigatus, mediated by Agrobacterium tumefaciens. In addition, a high throughput hydrogen peroxide screening system was established to examine $\sim 1,000$ mutants. A total of 100 mutants exhibited changes in hydrogen peroxide sensitivity, among which a significant increase in sensitivity was observed in the AFM2658 mutant. Further investigations of the mutant were also performed, in which the sequence of this mutant was characterized using thermal asymmetric interlaced-polymerase chain reaction. This revealed that the insertion site was located on chromosome 2 afu1_92, and the 96 bp sequence was knocked out, which partially comprised a sequence localized between the integral membrane protein coding region and the helix-loop-helix transcription factor coding region. A decrease in the levels of anti-oxidative stress-associated mRNAs were observed, and an increase in reactive oxygen species were
\end{abstract}

Correspondence to: Professor Li Wang, Department of Pathogenobiology, Jilin University Mycology Research Center, Key Laboratory of Pathobiology, Ministry of Education, College of Basic Medical Sciences, Jilin University, 126 Xinmin Street, Changchun, Jilin 130021, P.R. China

E-mail: wli99@jlu.edu.cn

Key words: Aspergillus fumigatus, Agrobacterium tumefaciens, anti-oxidative stress, thermal asymmetric interlaced-polymerase chain reaction detected using fluorescence. The results of the present study demonstrated that this sequence may have a protective role in A. fumigatus in the presence of oxidative stress.

\section{Introduction}

Aspergillus fumigatus is one of the most common opportunistic pathogenic fungi, and is able to survive in various environmental conditions. Although several Aspergillus species can cause clinical infections, A. fumigatus accounts for $>70 \%$ of cases (1-3). Although immunosuppressive regimens, which target hematological malignancies and tumors, have been commonly utilized, and have also been used in organ transplantation, the morbidity rates of invasive aspergillosis (IA) have been increasing exponentially in previous years. Thus, an increasing number of investigations have focussed on this fungus, as understanding the pathogenic mechanism of A. fumigatus is important (4). In 2005, the whole genome of A. fumigatus was sequenced, which provided a precondition for further comprehensive investigations of this fungal pathogen (4).

An association between the virulence of A. fumigatus and the immune condition of the host can be deduced from the characteristics of the susceptible population. When A. fumigatus invasion occurs in humans, the innate immune system performs a crucial role in scavenging the fungus (5). Alveolar macrophages eliminate the conidia of A.fumigatus by NADPH oxidase, whereas prevention against hyphae and immune-evading conidia is mediated by neutrophils, which use respiratory bursting to generate reactive oxygen species (ROS) and form neutrophilic extracellular traps $(6,7)$. The importance of anti-oxidative stress in the contribution to A. fumigatus virulence is clearly demonstrated in patients suffering from chronic granulomatous deficiency, who carry allosome-recessive inheritance mutations in components of the oxidase failing in superoxide anion synthesis, who frequently present with IA $(6,7)$. In previous studies on anti-oxidative stress of fungi, the majority of the investigations 
have concentrated on Saccharomyces cerevisiae and Candida albicans. However, the genetic association among A.fumigatus and the two species are distant, and only certain transcription factors and ROS-scavenging proteins have been validated as being associated with anti-oxidative stress in A. fumigatus (8-12). Therefore, comprehensive investigations are necessary to identify novel associated genes and elucidate their functions to overcome the limitations of conventional treatment methods $(13,14)$.

Functional genomics is a genetic strategy, which depends on a stable transformation system and specific screening methods to determine certain function-associated genes (15). Agrobacterium tumefaciens-mediated transformation (ATMT) has been widely used for botanical and fungal genetic manipulation. A. tumefaciens can transfer part of a plasmid (transferred DNA; T-DNA) into the genome of a host to produce mutants. ATMT has shown several advantages, including higher transformation frequency, more stable transformants with a single T-DNA copy and various available acceptors (16). T-DNA is composed of a right border (RB), left border (LB) and the sequences between them. An efficient polymerase chain reaction (PCR) method can be used to analyze the disrupted genes by amplification of the flanking sequences of RB and LB $(15,16)$. Genome-wide mutant libraries of Magnaporthe oryzae and Arabidopsis, based on ATMT, have been established $(17,18)$. With the availability of the complete genome of A.fumigatus, the functional genomics, based on ATMT, can be examined to contribute to a better understanding of the gene functions, and to identify novel genes or pathways involved in anti-oxidative stress. This may aid in providing novel targets for the treatment of IA.

In the present study, a number of randomly-inserted mutants of A.fumigatus, mediated by A.tumefaciens were identified. $\mathrm{H}_{2} \mathrm{O}_{2}$ was used as a screening reagent. Several mutants exhibited changes in $\mathrm{H}_{2} \mathrm{O}_{2}$ sensitivity, among which a relatively marked increase in sensitivity was observed in the AFM2658 mutant. The insertional site of AFM2658 was then characterized, and the mutant was compared with the wild-type in terms of the diameter of colonies, and levels of ROS and mRNA, to determine whether the sequence alteration increases $\mathrm{H}_{2} \mathrm{O}_{2}$ sensitivity.

\section{Materials and methods}

Fungal strains and plasmid. A. fumigatus (IFM40808; wild-type) was provided by the Medical Mycology Research Center of Chiba University (Chiba, China). The strain was cultured at $28^{\circ} \mathrm{C}$ on potato dextrose agar (PDA; BD Biosciences, San Diego, CA, USA). The A.tumefaciens strain, AGL-1, was provided by Professor Zhonghua Wang of Fujian Agriculture and Forestry University (Fujian, China), as was the $\mathrm{pBHt}$ 1 vector, harboring the hygromycin B phosphotransferase $(h p h)$ gene as the selection tag under the regulation of the Aspergillus nidulans trpC promoter (19).

ATMT transformation. The transformation process was modified based on a preliminary study (18). AGL-1, carrying pBHt1, was cultured at $28^{\circ} \mathrm{C}$ in $10 \mathrm{ml}$ Luria-Bertani (LB) medium, with $20 \mu \mathrm{g} / \mathrm{ml} \mathrm{rifampicin} \mathrm{and} 100 \mu \mathrm{g} / \mathrm{ml}$ kanamycin for $24 \mathrm{~h}$ in a rotatory shaker $(200 \mathrm{rpm})$. Subsequently $\sim 3.0 \mathrm{ml}$ of the culture was centrifuged at 2,400 $\mathrm{g}$ for $10 \mathrm{~min}$, and the precipitate was resuspended in inducible medium supplemented with $200 \mu \mathrm{M}$ acetosyringone to achieve an optical density (OD) of between 0.2 and 0.4 at $600 \mathrm{~nm}$ by a microplate reader (Molecular Devices, Sunnyvale, CA, USA). The medium was cultured with agitation at $140 \mathrm{rpm}$ at $28^{\circ} \mathrm{C}$ for $8-10 \mathrm{~h}$ until an $\mathrm{OD}_{600 \mathrm{~nm}}$ value of $0.8,0.9$ or 1.0 was reached. A. fumigatus (IFM40808) was cultured on PDA at $28^{\circ} \mathrm{C}$ for 5 days. The conidia were then scraped from the clones into moderate $0.9 \%$ sodium chloride solution with $0.1 \%$ Tween 80 Sigma-Aldrich (St. Louis, MO, USA) to attain final concentrations of $10^{6}, 10^{7}$ and $10^{8}$ conidia/ml.

Sterile microporous filters $(0.45 \mu \mathrm{m}, \mathrm{GE}$ Healthcare Life Sciences Logan, UT, USA) were placed on solid IM+AS plates. A total of $100 \mu \mathrm{l}$ of each AGL-1 culture was mixed with an equal volume of the corresponding concentration of the IFM40808 conidia, and pipetted onto the filters. The plates were cultured at 20,23 or $25^{\circ} \mathrm{C}$ for 36,48 or $60 \mathrm{~h}$. The filters were then transferred onto selection media (SM; which consisted of PDA with $200 \mu \mathrm{M}$ cefotaxime and $100 \mu \mathrm{g} / \mathrm{ml}$ hygromycin B; both from Sigma-Aldrich) at $37^{\circ} \mathrm{C}$ in the dark, until colonies of the mutants appeared. Sterile sticks were used to transfer the monocolonies into freezing tubes containing $\mathrm{SM}$, and were cultured at $37^{\circ} \mathrm{C}$ in the dark for $\sim 48 \mathrm{~h}$. The colonies were stored at $4^{\circ} \mathrm{C}$ only when spore germination occurred.

Molecular analysis of mutants. Analysis of the insertion sequence was performed, according to a previously described method $(16,20)$. Briefly, the mutants were cultured in PDB at $28^{\circ} \mathrm{C}$ for $24 \mathrm{~h}$, following which the mycelia were collected and centrifuged at 5,600 $\mathrm{x}$ g for $1 \mathrm{~min}$ at $4^{\circ} \mathrm{C}$. DNA was extracted using a DNA extraction kit (Takara Biotechnology, Co., Ltd., Dalian, China) according to the manufacturer's instructions. The insertion of the $h p h$ gene was identified using PCR amplification with forward and reverse $h p h$ primers (Table II). The PCR reaction contained $2.5 \mu \mathrm{l}$ of $10 \mathrm{X}$ loading buffer, $5 \mathrm{nmol}$ dNTP, 1.25 units Taq, 10 pmol hph-f and hph-r, and $100 \mathrm{ng}$ DNA. The total volume was $25 \mu \mathrm{l}$. The PCR recycling was performed as follows: Template denaturation at $95^{\circ} \mathrm{C}$ for $2 \mathrm{~min}$, 35 cycles of $94^{\circ} \mathrm{C}$ for $30 \mathrm{sec}, 52^{\circ} \mathrm{C}$ for $30 \mathrm{sec}, 72^{\circ} \mathrm{C}$ for $1 \mathrm{~min}$, followed by $72^{\circ} \mathrm{C}$ for $10 \mathrm{~min}$. TAIL-PCR was performed, as described previously (16), and was used to identify the T-DNA flanking sequences of the mutants (Table II). All PCR amplifications were performed on a Takara PCR Thermal Cycler Dice (Takara Bio, Inc., Shiga, Japan). The reaction products were sequenced by Shenggong Co., Ltd. (Beijing, China).

Identification of $\mathrm{H}_{2} \mathrm{O}_{2}$ concentrations and primary screening. A $5 \mu 1$ suspension of the IFM40808 conidia, with a concentration of $2 \times 10^{7}$ conidia/ml, was spotted on PDA plates containing different concentrations of $\mathrm{H}_{2} \mathrm{O}_{2}(0,0.5,1.0,1.5,2.0,2.5,3.0$ and $3.5 \mathrm{mM}$ ), and incubated in the dark at $28^{\circ} \mathrm{C}$ for 3 days to determine the final screening concentrations. Subsequently, between 30 and 40 CFU reactivated mutants of IFM40808 were added to PDA plates with $\mathrm{H}_{2} \mathrm{O}_{2}$ and cultured at $28^{\circ} \mathrm{C}$ for 3 days. The strains exhibiting clear growth restriction were selected for further experiments.

Fluid quantitative screening. The conidia of the $\mathrm{H}_{2} \mathrm{O}_{2}$-sensitive mutants and wild types were collected, and conidia suspensions 
were established $\left(10^{7}\right.$ conidia/ml $)$, comprising $10 \mu 1$ conidia suspended in $5 \mathrm{ml}$ PDB containing serial concentrations of $\mathrm{H}_{2} \mathrm{O}_{2}(2,2.5,3.0,3.5$ and $4.0 \mathrm{mM})$. The suspension was then incubated at $28^{\circ} \mathrm{C}$ for $72 \mathrm{~h}$. The turbidity of the PDB was evaluated by the naked eye and used to determine whether the strains grew.

Growth curves of colony diameter. Triplicate $5 \mu 1$ suspensions of conidia $\left(2 \times 10^{7}\right.$ conidia/ml $)$ of the sensitive mutants were exposed to PDA with either $\mathrm{H}_{2} \mathrm{O}_{2}(0,2,2.5$ and $3 \mathrm{mM})$ or menadione $(20,40$ and $60 \mu \mathrm{M})$, and were cultured at $28^{\circ} \mathrm{C}$ for 3 days. Sequential measurements of the diameters of the colonies were performed in each condition.

Spot assay. Conidia were diluted serially to determine the defined concentrations. Conidia at concentrations of $\sim 10^{5}, 10^{4}$, $10^{3}$ and $10^{2}$, in a volume of $5 \mu \mathrm{l}$, were spotted on PDA with or without $2.5 \mathrm{mM} \mathrm{H}_{2} \mathrm{O}_{2}$, and then incubated at $37^{\circ} \mathrm{C}$ for $48 \mathrm{~h}$ (21).

Protoplast preparation. The procedure was based on a previously described method with modification (22). Briefly, $10^{8}$ fresh conidia were added to normal saline containing $0.4 \%$ Tween 80 , and then injected into $10 \mathrm{ml}$ of Czapek (Sigma-Aldrich) or PDB culture. The cultures were centrifuged for $15 \mathrm{~min}$ at $2,400 \mathrm{x}$ g once the germination rate reached $80 \%$. The precipitate was then cleaned using $0.6 \mathrm{M} \mathrm{KCl}$ solution. The resulting product was processed by $4 \mathrm{ml} 1.2 \mathrm{M}$ sorbitol- $10 \mathrm{mM}$ potassium phosphate ( $\mathrm{pH} 5.8$ ), containing either $1 \mathrm{mg} / \mathrm{ml}$ helicase (Sangon Biotech, Shanghai, China), $1 \mathrm{mg} / \mathrm{ml}$ cellulose (Sangon Biotech) and $5 \mathrm{mg} / \mathrm{ml}$ lywallzyme (GIMCC, Guangzhou, China), or $5 \mathrm{mg} / \mathrm{ml}$ helicase, $5 \mathrm{mg} / \mathrm{ml}$ cellulose and $10 \mathrm{mg} / \mathrm{ml} \mathrm{lywallzyme.} \mathrm{The} \mathrm{mixtures} \mathrm{were} \mathrm{then} \mathrm{incubated} \mathrm{in}$ a shaker $(140 \mathrm{rpm})$ at 28 or $30^{\circ} \mathrm{C}$. The duration was determined by the microscopic examination (Nikon YS2-H, Tokyo, Japan). When a high yield of protoplasts was obtained, centrifugation was performed at $2,000 \mathrm{x} \mathrm{g}$ for $20 \mathrm{~min}$. The residual enzyme was eliminated using $0.6 \mathrm{M} \mathrm{KCl}$ solution, and the precipitate was resuspended with the regenerated buffer, containing $1 \mathrm{M}$ sorbitol and $10 \mathrm{mM}$ Tris- $\mathrm{HCl}(\mathrm{pH} 7.5)$. The protoplasts were immediately used in the subsequent experiments.

\section{2,7-dichlorofluorescin diacetate (DCFH-DA) staining} DCFH-DA (Sigma-Aldrich, St. Louis, MO, USA; $10 \mu \mathrm{M}$ ) was added to the protoplast sample at a volume of $0.1 \%$. The mixture was incubated at $37^{\circ} \mathrm{C}$ for $30 \mathrm{~min}$, and then centrifuged at 4,000 $\mathrm{rpm}$ for $20 \mathrm{~min}$. The supernatant was discarded, and $0.6 \mathrm{M} \mathrm{KCl}$ solution was used to resuspend the precipitate, which was then centrifuged and resuspended in moderate regeneration buffer. Different volumes of $\mathrm{H}_{2} \mathrm{O}_{2}$ were added to the protoplast solution, to produce final concentrations of $0,0.6$ and 2.4 , which were then incubated at $37^{\circ} \mathrm{C}$ for 0,30 and $60 \mathrm{~min}$, respectively. The conidia were visualized using an Olympus FV1000 confocal laser microscope (Olympus Corporation, Tokyo, Japan) to determine the ROS levels.

Determination of the mRNA levels of oxidative stress-assiociated genes. The conidia suspension $\left(\sim 10^{8}\right)$ was added to and incubated with $10 \mathrm{ml} \mathrm{PDB}$ at $28^{\circ} \mathrm{C}$ for $48 \mathrm{~h}$ in a rotatory shaker $(140 \mathrm{rpm})$. The moderate $\mathrm{H}_{2} \mathrm{O}_{2}$ was then added to
Table I. Primers used for polymerase chain reaction analysis.

\begin{tabular}{ll}
\hline Primer & \multicolumn{1}{c}{ Primer sequence } \\
\hline GAPDH-f & 5'-CGTTGAGAGAAGGAATGAC-3' \\
GAPDH-r & 5'-AAATACGACACCACCCAC-3' \\
Hyr1-f & 5'-GGCATCATCTCCTTCATC-3' \\
Hyr1-r & 5'-ACTATCGCCTCCTTCCAT-3' \\
HLH-f & 5'-TGGTTACAACTCTCATTGGG-3' \\
HLH-r & 5'-TATCCTCAAGCCAGTCAGC-3' \\
IMP-f & 5'-GCAGAAGAAGAACGGGTAAG-3' \\
IMP-r & 5'-TAGCAACGAACCACTGACC-3' \\
AfYap1-f & 5'-ACTCTCCATCGTCCTCTT-3' \\
AfYap1-r & 5'-CTCCTCATCTTCATCCAGT-3'
\end{tabular}

GAPDH, glyceraldehyde-3 phosphate dehydrogenase; HLH, helix-loop-helix transcription factor; IMP, integral membrane protein; $\mathrm{f}$, forward, $r$, reverse.

Table II. Primers used for thermal asymmetric interlaced-polymerase chain reaction analysis.

\begin{tabular}{ll}
\hline Primer & \multicolumn{1}{c}{ Primer sequence } \\
\hline LB1 & 5'-GGGTTCCTATAGGGTTTCGCTCATG-3' \\
LB2 & 5'-CATGTGTTGAGCATATAAGAAACCCT-3' \\
LB3 & 5'-GAATTAATTCGGCGTTAATTCAGT-3' \\
RB1 & 5'-GGCACTGGCCGTCGTTTTACAAC-3' \\
RB2 & 5'-AACGTCGTGACTGGGAAAACCCT-3' \\
RB3 & 5'-CCCTTCCCAACAGTTGCGCA-3' \\
AD1 & 5'-CAAGCAAGCA-3' \\
AD2 & 5'-CATCGNCNGANACGAA-3' \\
AD3 & 5'-AGTGNAGAANCAAAGG-3' \\
AD4 & 5'-TGAGNAGTANCAGAGA-3' \\
hph-f & 5'-CGCCCAAGCTGCATCATCGAA-3' \\
hph-r & 5'-CGACAGCGTCTCCGACCTGA-3'
\end{tabular}

$\mathrm{LB}$, left border; $\mathrm{RB}$, right border; $\mathrm{AD}$, arbitrary regenerate; hph, f, hygromycin B phosphotransferase; forward; r, reverse.

obtain a final concentration to $3 \mathrm{mM}$. Following stimulation of the mycelia for 3 and $6 \mathrm{~h}$, the mycelia were leached and TRIzol was used to extract the total RNA (Invitrogen; Thermo Fisher Scientific, Inc., Waltham, MA, USA). First strand cDNA were generated, according to the manufacturer's protocol (Promega Corporation, Madison, MI, USA). The levels of the glutathione peroxidase Hyrl gene, AfYapl gene, integral membrane protein (IMP) gene and helix-loop-helix transcription factor (HLH) gene were normalized by glyceraldehyde- 3 phosphate dehydrogenase. The corresponding primers used are listed in Table I. cDNA primers were designed, according to those in GeneBank (http://www.ncbi. nlm.nih.gov/genbank). The PCR products underwent electrophoresis on $0.8 \%$ agarose gel with ethidium bromide, and were analyzed using a gel imaging system (1600-GIS 1D; Tanon, Shanghai, China). 
Anti-fungal drug susceptibility assessment. Itraconazole, voriconazole, fluconazole and amphotericin B (Sigma-Aldrich) were selected to determine the susceptibility of A.fumigatus IFM40808 and the AFM2658 mutant (23). All agents were serially diluted 2 -fold to achieve the final concentration range of $0.0156-16 \mu \mathrm{g} / \mathrm{ml}$. Conidia $(5,000)$ were challenged by the agents for $24 \mathrm{~h}$ at $37^{\circ} \mathrm{C}$. The OD at $600 \mathrm{~nm}$ was measured. All experiments described above were performed three times.

Statistical analysis. The mean \pm standard deviation of the colony diameters was performed by GraphPad Prism 5 software (GraphPad Software, Inc., La Jolla, CA, USA). The quantitation of the results of electrophoresis was analyzed by Quantity One (Bio-Rad, Hercules, CA, USA). Data were analyzed with SPSS 16.0 (SPSS Inc., Chicago, IL, USA). $\mathrm{P}<0.05$ was viewed as statistically significant.

\section{Results}

Optimization of the ATMT system for A. fumigatus. Mutant cultures of $\sim 100-120 /$ plate were achieved using the ATMT system when $10^{8}$ conidia/ml was co-cultivated with $A$. tumefaciens $\left(\mathrm{OD}_{600 \mathrm{~nm}}\right.$ of 0.8$)$ at $20^{\circ} \mathrm{C}$ for $48 \mathrm{~h}$. The sum of the mutants was $\sim 4,000$. The fungal background was clear, with a true positive rate of $\sim 95 \%$. The true positive rate indicated the percentage of true mutants from all the colonies, which survived culture with hygromycin B twice, followed by verification of T-DNA insertion using PCR, (Fig. 1; Table III).

AFM2658 exhibits higher levels of sensitivity towards $\mathrm{H}_{2} \mathrm{O}_{2}$, compared with IFM40808. When IFM40808 was grown for 3 days without $\mathrm{H}_{2} \mathrm{O}_{2}$, the average colony diameter was $35 \mathrm{~mm}$, whereas following culture with $2.5 \mathrm{mM} \mathrm{H}_{2} \mathrm{O}_{2}$, the diameter was $31 \mathrm{~mm}$. Thus, this concentration of $\mathrm{H}_{2} \mathrm{O}_{2}$ was selected as the primary selection concentration. Selection among the 1,000 mutants was performed by comparing the colony diameter with that of IFM40808. The colonies exhibiting significant inhibition were selected for further selection experiments. Without $\mathrm{H}_{2} \mathrm{O}_{2}$, the average diameter of the AFM2658 colonies reached $36 \mathrm{~mm}$ after 3 days. However, when the cultures were treated with 2 and $3 \mathrm{mM} \mathrm{H}_{2} \mathrm{O}_{2}$, the average diameters of IFM40808 reached 35 and $29 \mathrm{~mm}$, whereas in AFM2658, the diameters were 32 and $19 \mathrm{~mm}$ (Figs. 2 and 3). Following culture in PDB with 2 and $2.5 \mathrm{mM} \mathrm{H}_{2} \mathrm{O}_{2}$, AFM2658 and IFM40808 were turbid with dark green pellicles. IFM40808 with 3 and $3.5 \mathrm{mM} \mathrm{H}_{2} \mathrm{O}_{2}$ retained the ability to germinate, compared with the non-viable conidia of AFM2658. Neither survived following culture with $4 \mathrm{mM} \mathrm{H}_{2} \mathrm{O}_{2}$ (Fig. 4).

With $20 \mu \mathrm{M}$ menadione, the average diameters of the two strains was $22 \mathrm{~mm}$. On the PDA plates containing $40 \mu \mathrm{M}$, the diameter of AFM2658 was $18 \mathrm{~mm}$, whereas that of IFM40808 was $17 \mathrm{~mm}$. With $60 \mu \mathrm{M}$ menadione, the strains were inhibited to the size of $12 \mathrm{~mm}$ (data not shown).

In the spot assay, in which $10^{5}, 10^{4}, 10^{3}$ and $10^{2}$ conidia cultured on PDA plates without reagents for 2 days, the average diameter for the two strains were 27, 24, 21 and $18 \mathrm{~mm}$, respectively. Culture of $10^{5}, 10^{4}, 10^{3}$ and $10^{2}$ conidia with $2.5 \mathrm{mM} \mathrm{H}_{2} \mathrm{O}_{2}$, resulted in average diameters of 21,15 , $8,0 \mathrm{~mm}$, respectively for AFM2658, and 23, 19, 13 and $0 \mathrm{~mm}$ respectively for IFM40808 (Fig. 5).
Table III. Effects of temperature on the rate of Agrobacterium tumefaciens-mediated transformation of Aspergillus fumigatus.

\begin{tabular}{lcr}
\hline Temperature $\left({ }^{\circ} \mathrm{C}\right)$ & $\begin{array}{c}\text { True positive } \\
\text { rate }(\%)\end{array}$ & $\begin{array}{c}\text { False positive } \\
\text { rate }(\%)\end{array}$ \\
\hline 25 & $36.7 \pm 2.6$ & $63.7 \pm 2.6$ \\
20 & $95.2 \pm 1.7$ & $4.8 \pm 1.7$ \\
\hline
\end{tabular}

True positive rate indicates the percentage of true mutants that survived treatment with hygromycin B twice, followed by verification of T-DNA insertion by polymerase chain reaction, with the opposite representing the false positive rate. The experiments were repeated three times.

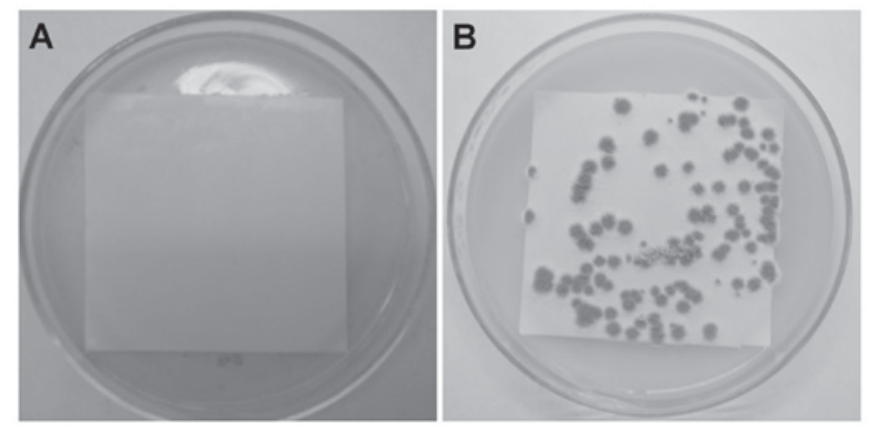

Figure 1. Randomly inserted mutation of IFM40808 by Agrobacterium tumefaciens. (A) Aspergillus fumigatus without A.tumefaciens, as a negative control; (B) A. fumigatus with A. tumefaciens.

Identification of the inter-region of AFM2658 between the two coding regions. The $\mathrm{RB}$ and $\mathrm{LB}$ flanking sequences were obtained using TAIL-PCR. Following Blast of the A. fumigatus Af293 whole genome, the insertion site was located on chromosome 2 afu1_92, and the 96 bp sequence was knocked out using T-DNA (5'-CTGAACAGAAAACACTCGGTT GTTCTTTGGCGCGGTATCTACCTTATCCACTCTTGC TCCTTTGAGAACTCTGGGATCGTCCAAATCGCACCC TAC-3'). This site was located between the IMP coding region and the HLH coding region. The inter-region sequence was $\sim 1,500$ bp. The RB was on the 5' site for $\sim 300$ bp of the HLH transcription factor coding region, and LB was on the $5^{\prime}$ site for 400 bp (Fig. 6).

ROS production in AFM2658 is increased when exposed to $\mathrm{H}_{2} \mathrm{O}_{2}$. The enzymolysis of conidia was most marked following incubation with $5 \mathrm{mg} / \mathrm{ml}$ hlicase $-5 \mathrm{mg} / \mathrm{ml}$ cellulase- $10 \mathrm{mg} / \mathrm{ml}$

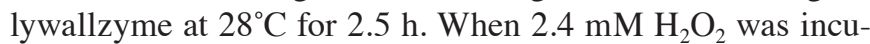
bated with AFM2658 for $60 \mathrm{~min}$, asymmetrical high green fluorescence was observed, attached to the cell membrane. By contrast, 30 min with $0.6 \mathrm{mM} \mathrm{H}_{2} \mathrm{O}_{2}$, a lower level of fluorescence was observed. All IFM40808 groups had lower green fluorescence, compared with AFM2658 that was treated with $2.4 \mathrm{mM} \mathrm{H}_{2} \mathrm{O}_{2}$ for $60 \mathrm{~min}$ (Fig. 7).

Anti-oxidative stress-associated genes are transcribed differently. The results of the PCR showed that the mRNA level of 


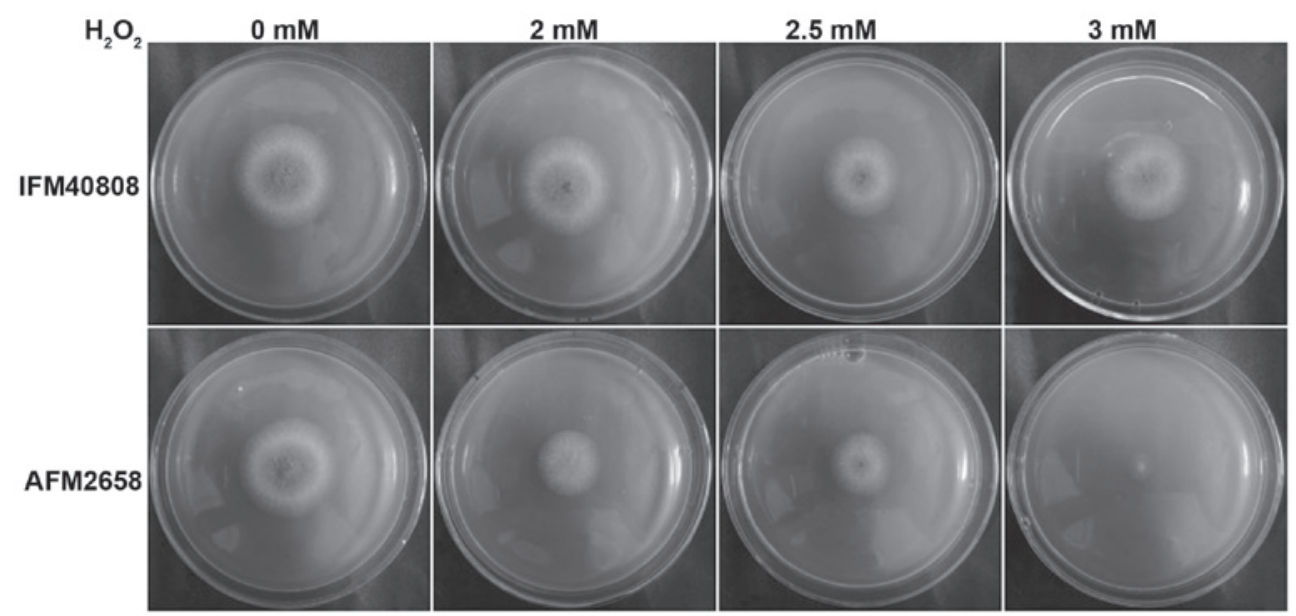

Figure 2. Sensitivity of the IFM40808 and AFM2658 Aspergillus fumigatus strains to $\mathrm{H}_{2} \mathrm{O}_{2}$. The conidia of the two strains were spotted onto PDA plates containing $\mathrm{H}_{2} \mathrm{O}_{2}$, at different concentrations.

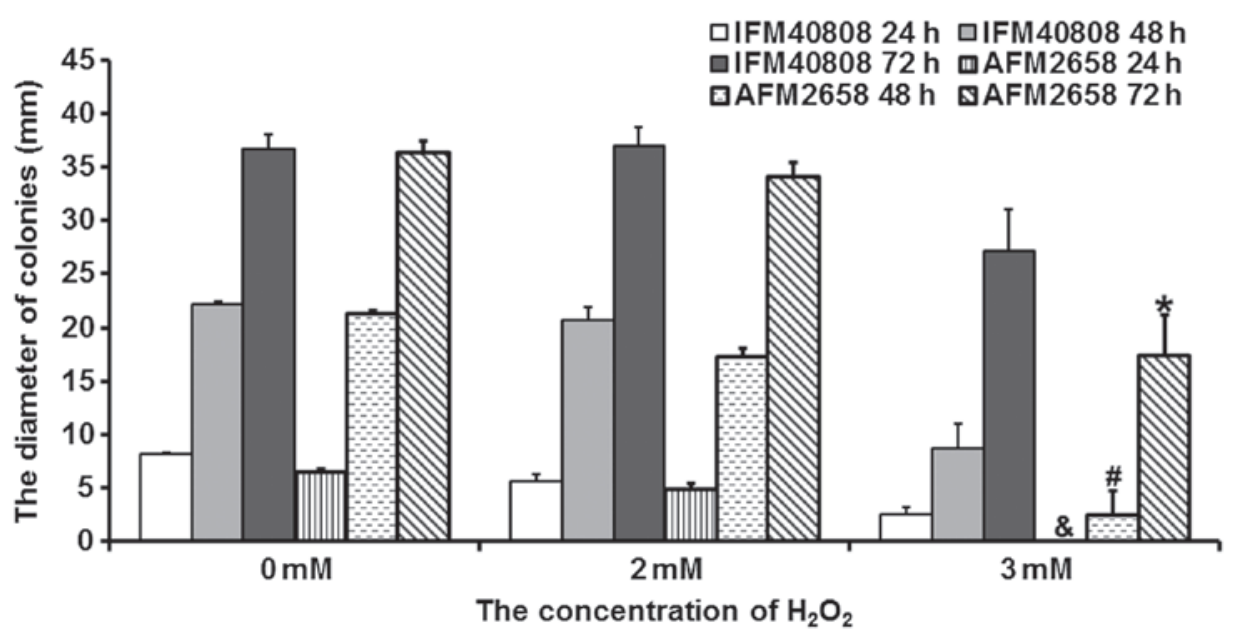

Figure 3. Colony diameter, indicating the sensitivity of IFM40808 and AFM2658 to $\mathrm{H}_{2} \mathrm{O}_{2}$. The diameter of the colonies following treatment with serial concentrations of $\mathrm{H}_{2} \mathrm{O}_{2}$ over time were measured. The inhibition of Aspergillus fumigatus increased as concentrations increased. A concentration of $2 \mathrm{mM}$ $\mathrm{H}_{2} \mathrm{O}_{2}$ limited growth marginally, whereas the decrease was more marked at a concentration of $3 \mathrm{mM} \mathrm{H}_{2} \mathrm{O}_{2}$. Data was presented as the mean \pm standard deviation, $\mathrm{n}=3$. ${ }^{*} \mathrm{P}<0.05$, compared with the IFM40808 cultured for $72 \mathrm{~h} .{ }^{*} \mathrm{P}<0.05$, compared with IFM 40808 cultured for $48 \mathrm{~h}$; ${ }^{\&} \mathrm{P}<0.05$, compared with IFM40808 cultured for $24 \mathrm{~h}$.

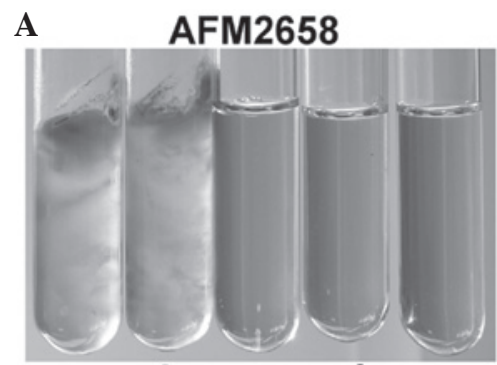

B IFM40808

a

b

C

d e

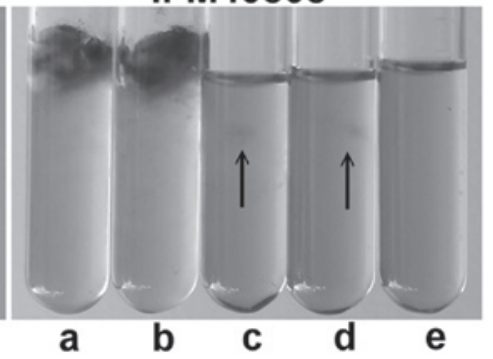

Figure 4. Fluid quantitative assessment to determine sensitivity to $\mathrm{H}_{2} \mathrm{O}_{2}$. The conidia of the two strains of Aspergillus fumigatus were inoculated into potato dextrose broth with $\mathrm{H}_{2} \mathrm{O}_{2}$ at concentrations of (a) 2, (b) 2.5, (c) 3, (d) 3.5 and (e) $4 \mathrm{mM}$. When cultured in PDB with 2 and $2.5 \mathrm{mM} \mathrm{H}_{2} \mathrm{O}_{2}$, (Aa and Ab) AFM2658 and ( $\mathrm{Ba}$ and $\mathrm{Bb}$ ) IFM40808 were turbid with dark pellicles. (Bc and Bd) IFM40808 with 3 and $3.5 \mathrm{mM} \mathrm{H}_{2} \mathrm{O}_{2}$ retained the ability to germinate, thus conidia or mycelia (arrows) were observed in the tube compared with the non-viable conidia of (Ac and Ad) AFM2658. (Ae and Be) Neither survived following culture with $4 \mathrm{mM} \mathrm{H}_{2} \mathrm{O}_{2}$.

HLH in IFM40808 decreased following treatment with $3 \mathrm{mM}$ $\mathrm{H}_{2} \mathrm{O}_{2}$ for $3 \mathrm{~h}$, but increased following treatment with $3 \mathrm{mM}$ $\mathrm{H}_{2} \mathrm{O}_{2}$ for 6 h. Compared with IFM40808, the basal level of
HLH in AFM2658 remained low. Following treatment with $\mathrm{H}_{2} \mathrm{O}_{2}$ for $3 \mathrm{~h}$, a marginal increase occurred, however, this was reversed when treated with $\mathrm{H}_{2} \mathrm{O}_{2}$ for $6 \mathrm{~h}$. Notably, the mRNA 


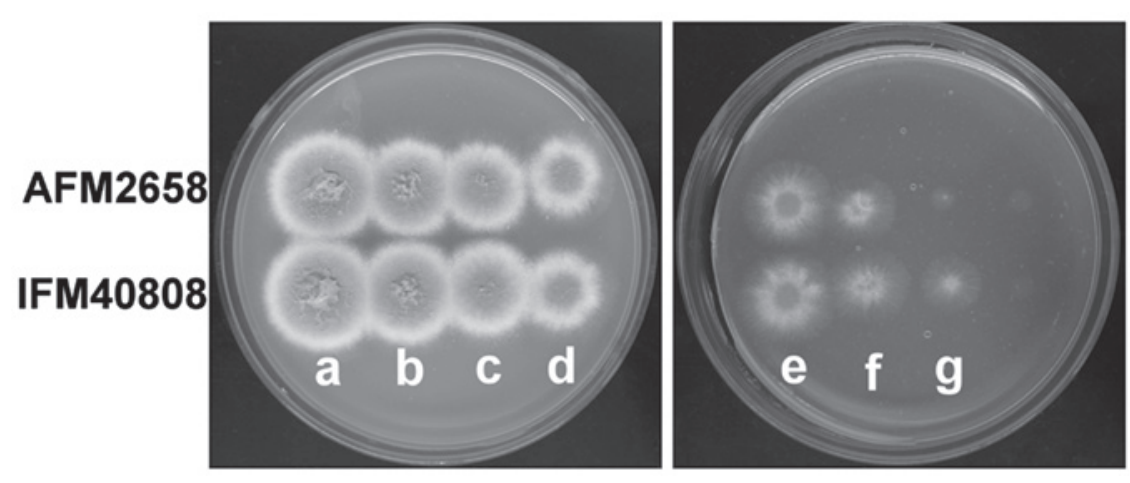

Figure 5. Spot assay for comparison of the sensitivities to $\mathrm{H}_{2} \mathrm{O}_{2}$ between the IFM40808 and AFM2658 strains. (a) $10^{5}$, (b) $10^{4}$, (c) $10^{3}$ and (d) $10^{2}$ conidia, in a volume of $5 \mu \mathrm{l}$, were spotted on a potato dextrose agar plate without $\mathrm{H}_{2} \mathrm{O}_{2}\left(\mathrm{a}, \mathrm{b}\right.$, c and d) or treated with $\mathrm{H}_{2} \mathrm{O}_{2}(\mathrm{e} g$ and $\mathrm{f})$.

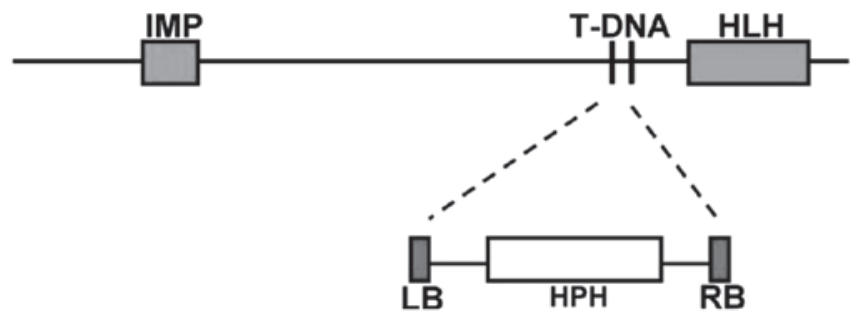

Figure 6. Analysis of T-DNA flanking sequences in AFM2658. The T-DNA is shown below the upper schematic, which represents the genome of Aspergillus fumigatus. The sequence replaced by T-DNA was analyzed. $\mathrm{LB}$, left border; RB, right border; HPH, hygromycin B phosphotransferase HLH, helix-loop-helix transcription factor coding region; IMP, integral membrane protein coding region.

level of IMP in IFM40808 was markedly upregulated following exposure to $\mathrm{H}_{2} \mathrm{O}_{2}$ for $6 \mathrm{~h}$, but not $3 \mathrm{~h}$. By contrast, the mRNA level of IMP in AFM2658 decreased when treated with $\mathrm{H}_{2} \mathrm{O}_{2}$.

Previous studies have shown hat GPX3 functions as an anti-oxidative enzyme, as well as an activator of transcription factor YAP1 in S. cerevisiae (24,25). Hyrl and AfYap1 of $A$. fumigatus are orthologs to GPX3 and YAP1, respectively. In the present study, the mRNA level of Hyrl increased initially, and decreased with increasing duration of treatment with $\mathrm{H}_{2} \mathrm{O}_{2}$ in the IFM40808 and AFM2658 strains. Following a short duration of $\mathrm{H}_{2} \mathrm{O}_{2}$ treatment, A. fumigatus upregulated the transcription of Hyrl and maintained a moderate expression levels of AfYap1, to provide adaptive responses to $\mathrm{H}_{2} \mathrm{O}_{2}$. Following treatment for $6 \mathrm{~h}$, the mRNA levels of Hyrl and AfYapl decreased markedly, and this appeared to be more marked in AFM2658. The expression levels of Hyr1 and AfYap1 were higher in IFM40808, compared with AFM2658 in every experimental condition (Fig. 8).

AFM2658 exhibits no changes in susceptibility to certain antifungal drugs. The AFM2658 and IFM40808 strains were not affected following exposure to minimum inhibitory concentrations of itraconazole or voriconazol $(31.25 \mathrm{pg} / \mathrm{ml}$ and $1 \mu \mathrm{g}$ / $\mathrm{ml}$, respectively). Fluconazole $(64 \mu \mathrm{g} / \mathrm{ml})$ and amphotericin B $(16 \mu \mathrm{g} / \mathrm{ml})$ also had no suppressive effects on either strain.

\section{Discussion}

The conidia of A. fumigatus are inhaled into the respiratory system and are immediately challenged by various environmental changes, particularly those derived from the innate immune system. The majority of the mechanisms of immune defense remain to be fully elucidated, however, a number of the reports have focused on intracellular or extracellular oxidative stress. ROS accounts for the majority of oxidative stress, and the inhalation of A. fumigatus can generate a certain level of ROS (26).

Several detoxifying strategies have been characterized in A. fumigatus and other fungi, including the thioredoxin and glutathione system, catalase and superoxide dismutase to detoxify the superoxide anion, $\mathrm{H}_{2} \mathrm{O}_{2}$, and hydroxylradical and its derivatives (5). The regulatory mechanism underlying the induction of in these anti-oxidative stress proteins remains to be fully elucidated. In previous studies of fungi, the ROS scavenger system of Saccharomyces cerevisiae has been analyzed more comprehensively $(24,27)$, and the mechanisms, which regulate the fungal response to oxidative stress have been established into two types: Activity regulation by protein phosphorylation and nuclear localization control (27). GPX3 is universally acknowledged as a peroxide sensor and important regulator of transcription factor YAP1, and it appears to account for the majority of activity to alleviate membrane phospholipid hydroperoxides (24). Yap1, acting as a responsive factor, can accumulate in the nucleus to activate the transcription of anti-oxidative-associated genes, including TRX2 and GSH1, due to a shift in its structure when the pathogen encounters ROS (24). Based on the homologous sequences of A. fumigatus with $S$. cerevisiae, it has been reported that AfYaplp and Skn7 knock-out strains of $A$. fumigatus exhibit higher levels of sensitivity to $\mathrm{H}_{2} \mathrm{O}_{2}(11,12)$.

Comparison with the model pathway of other fungi is not always an accurate strategy to determine the function of genes. In addition, the specific oxidant responsive pathways and the sensitivities to oxidative stress have an effect. For example, Msn2/4 has a significant role in $S$. cerevisiae and C. glabrata, however it has no effect on the response to oxidant stress in C. albicans, and in A. fumigatus, no homlogous sequence of Msn2/4 has been identified. Evidence indicates an evolutionary divergence in function among these fungi (28-31). In addition, it is difficult to obtain comprehensive understanding of anti-oxidative stress by focusing on a single gene. Previous investigations have knocked-out almost all the non-essential genes of $S$. cerevisiae, and $>600$ genes have been determined as anti-oxidative-associated genes (32). To obtain a further 


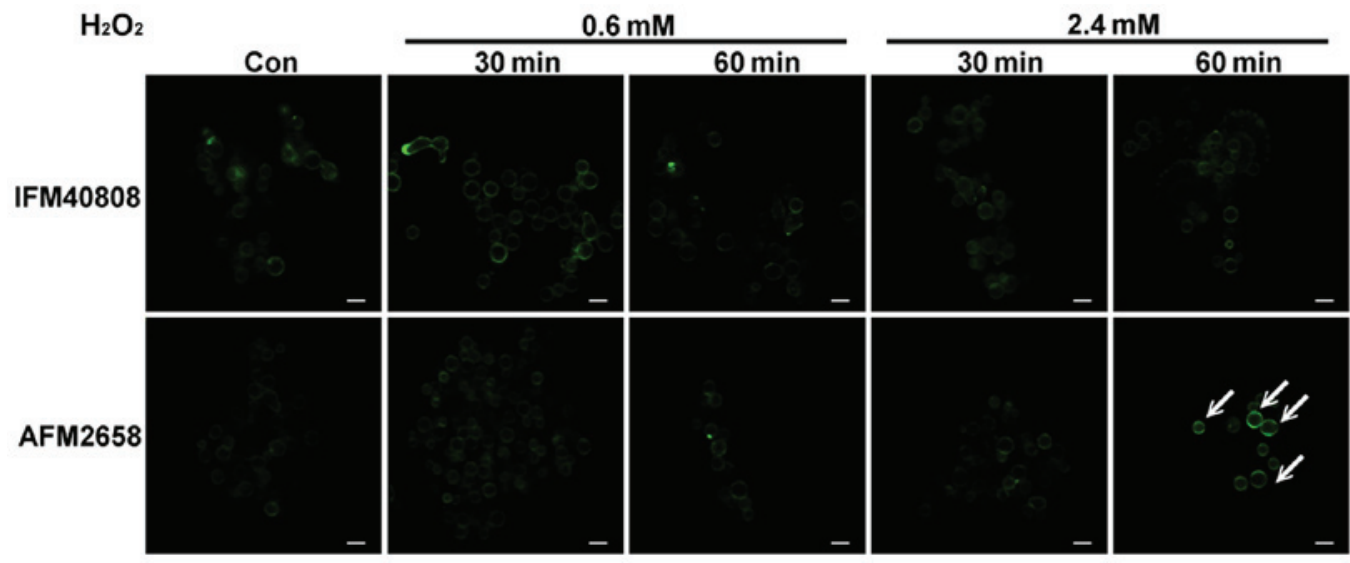

Figure 7. 2,7-Dichlorofluorescin diacetate staining was used to determine the ROS levels in the protoplasts treated with $\mathrm{H}_{2} \mathrm{O}_{2}$. The conidia were observed using fluorescence microscopy to determine the ROS levels. When $2.4 \mathrm{mM} \mathrm{H}_{2} \mathrm{O}_{2}$ was incubated with AFM2658 for 60 min, asymmetrical high green fluorescence was observed, attached to the cell membrane, and all IFM40808 groups had lower green fluorescence. (Scale bar=10 $\mu \mathrm{m}$ ). The arrows indicate ROS. ROS, reactive oxygen species; Con, control.

A

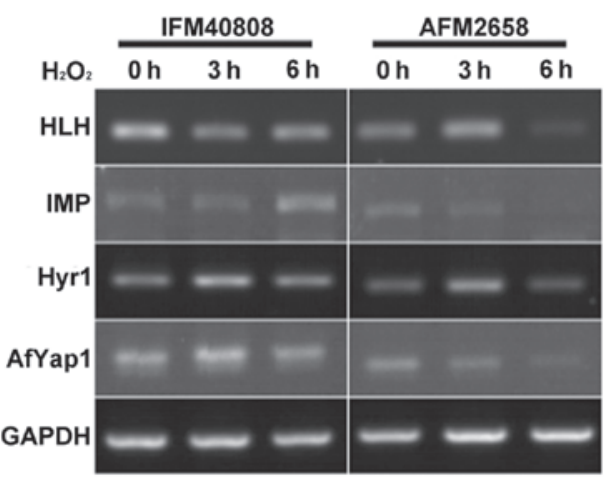

C

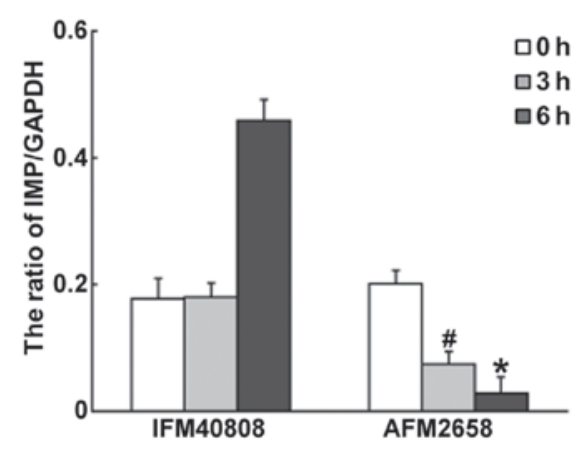

B

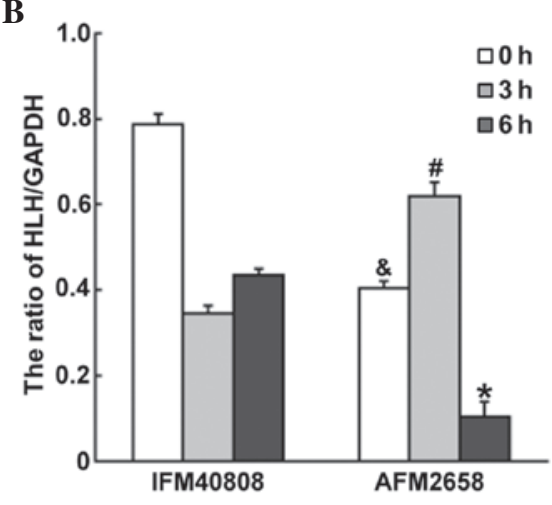

D
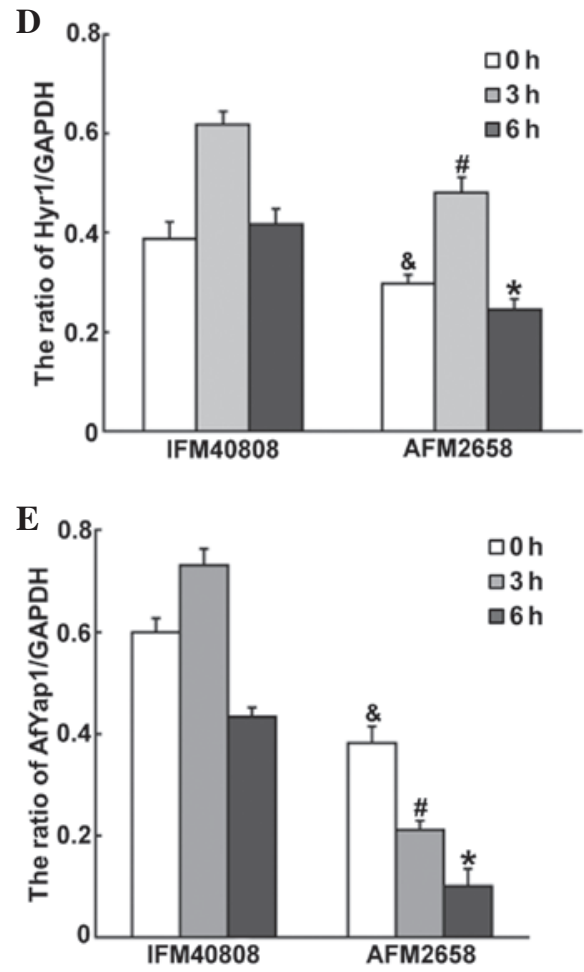

Figure 8. mRNA levels of anti-oxidative stress-associated genes in Aspergillus fumigatus strains treated with $\mathrm{H}_{2} \mathrm{O}_{2}$. cDNA were extracted and amplified using PCR analysis. (A) The PCR products underwent electrophoresis on agarose gel with ethidium bromide, and analyzed using a gel imaging system. The quantitation of (B) HLH, (C) IMP, (D) Hyr1 and (E) Afyap1 was performed. Data was presented as the mean \pm standard deviation, $\mathrm{n}=3$. "P $<0.05$, compared with IFM40808 treament for $6 \mathrm{~h}$; ${ }^{*} \mathrm{P}<0.05$, compared with IFM 40808 treatment for $3 \mathrm{~h}$; ${ }^{\circledR} \mathrm{P}<0.05$, compared with IFM 40808 cultured for 0 h. PCR, polymerase chain reaction; GAPDH, glyceraldehyde 3-phosphate dehydrogenase; HLH, helix-loop-helix transcription factor coding region; IMP, integral membrane protein coding region. 
understanding of anti-oxidative-associated genes, the present study constructed a transformed system, mediated by A. tumefaciens.

Following construction of the transformation system, 100-120 mutants were identified in $10^{7}$ conidia, which were almost the same frequencies of transformation as obtained in a previous study (25). Temperature appeared to have an effect in the ATMT of A.fumigatus, and $25^{\circ} \mathrm{C}$ was selected for co-cultivation due to the consensus of opinions that the optimal temperature for ATMT of the majority of filamentous fungi is between 22 and $25^{\circ} \mathrm{C}(25,33)$. However, at this temperature, regardless of co-cultivation conditions, few mutant monocolonies emerged, and a low true positive rate was recorded. It was observed that A. fumigatus germinated with white mycelia or generated dark-green conidia, prior to transfer to the selected media, and appeared to be more tolerant to hygromycin. To limit the redundant growing rate and realize the selection function of hygromycin, the temperature was decreased to 23 or $20^{\circ} \mathrm{C}$. As the growth of mutants at $23^{\circ} \mathrm{C}$ was almost equal to that at $20^{\circ} \mathrm{C}$, a temperature of $20^{\circ} \mathrm{C}$ was selected to ensure optimal conditions to obtain a higher true positive rate and clearer fungal background. This temperature was considered to suitable for the virulent proteins utilized by A.tumefaciens to transfer T-DNA. Of note, whereas attention has previously focussed on the term 'transformation frequencies', one of the main aims of randomly-inserted mutation is to acquire adequate mutants. Thus, a marginally reduced transformation frequency can be supplemented by increasing the amount of conidia, to obtain sufficient transformers on each plate. The present study aimed to identify novel anti-oxidative stress-associated genes using this randomly inserted transformation system.

Although no oxidant can represent natural oxidative stress (34), $\mathrm{H}_{2} \mathrm{O}_{2}$ is most widely used as a model for oxidative stress conditions (24). Thus, $\mathrm{H}_{2} \mathrm{O}_{2}$ was selected as the screening agent in the present study. A total of 100 mutants were screened as $\mathrm{H}_{2} \mathrm{O}_{2}$-sensitive candidates. These mutants were quantitatively screened, and 10 mutants were confirmed. Among these mutants, the inserted sites of eight mutants were coding regions (data not shown). The concentration of $\mathrm{H}_{2} \mathrm{O}_{2}$ tolerated by IFM 40808 was $1 \mathrm{mM}$ higher, compared with AFM2658. No differences were observed between the two strains without $\mathrm{H}_{2} \mathrm{O}_{2}$ treatment, which demonstrated that the disrupted gene was associated with the oxidative stress caused by $\mathrm{H}_{2} \mathrm{O}_{2}$, and not with growth. However, no significant differences were observed following treatment with menadione. Nikolaou et al also found that certain fungi were more resistant to menadione than $\mathrm{H}_{2} \mathrm{O}_{2}$ (28). This may be due to the fact that menadione predominantly induces superoxide anions, whereas peroxide is the major product of $\mathrm{H}_{2} \mathrm{O}_{2}$. Active electron transportation among these ROS substances makes it difficult to obtain a conclusion when the responses are attributable to the types of ROS.

A previous report demonstrated that azoles require intact mitochondrial function to exert their toxicity, and decreased intracellular generation of ROS may lead to reduced susceptibility of azoles (35). In the present study, antifungal drug susceptibility assessment was performed, and AFM2658 exhibited the same susceptibility as AFM40808, which may be explained by the specificity of the disrupted sequence, not associated with respiratory chains, and other pharmacological actions of azoles, including interrupting ergosterol synthetase function (36).

To identify whether the mechanism of fungal death by $\mathrm{H}_{2} \mathrm{O}_{2}$ was ROS-mediated, DCFH-DA staining was used in the present study. DCFH-DA fluorescence is not observed until it encounters intracellular esterase, and ROS can transform DCFH into DCF with notable fluorescence. A. fumigatus exhibits marked autofluorescence (AF), which affects the observation of ROS (37). AF is closely associated with compounds of the cell wall, in which chitin may have a significant role. Adding metal ions or altering the $\mathrm{pH}$ also affects the generation of $\mathrm{AF}(38,39)$. Therefore, protoplast preparation and culture adjustment was performed to acquire the least AF. The results revealed that the complete protoplasts, containing almost no cell wall, cultured in Czapek culture, exhibited lower levels of AF than the opposite. The present study observed that the increase in DCF-associated fluorescence was concentration- and time-dependent. The intensity of ROS fluorescence in AFM2658 was more marked, compared with that in IFM40808 when cultured in PDB with $2.4 \mathrm{mM} \mathrm{H}_{2} \mathrm{O}_{2}$ for $60 \mathrm{~min}$. Other groups had less marked differences. The regulation of anti-oxidative stress remained at lower concentrations and/or shorter processing duration. As the duration extended, the concentration increased, and anti-oxidant was exhausted or its generation was suppressed, leading to delayed ROS scavenging. The ROS may act as a pathway signal, which can induce cell apoptosis or destroy a wide range of molecules directly.

To further examine the changes in gene transcription following exposure to $\mathrm{H}_{2} \mathrm{O}_{2}$, the expression levels of anti-oxidative stress-associated genes in the fungi were detected using TAIL-PCR. Downregulation in the expression levels of Hyrl and Af Yap1 in AFM2658 were observed, which may have sensitized AFM2658 to $\mathrm{H}_{2} \mathrm{O}_{2}$. AfYap1 has been identified as the ortholog to YAP1 in S.cerevisiae (12). The RNA of Hyrl of A. fumigatus was assumed to encode a similar protein (GPX3) in S. cerevisiae (24).Based on the functions mentioned above, the present study hypothesized that the decreased expression of GPX3 may correspond with the decreased resistance to membrane phospholipid hydroperoxides, and also contribute to the weakened ability to mediate ROS signals to YAP1, resulting in the failure of nuclear localization of YAP1. Together with the change in the expression of YAP1, the expression levels of the downstream YAP1-targeted are likely to be affected. The expression levels of the two genes changed with the duration of stress. Therefore, the present study hypothesized that the fungi can regulate the transcription of the genes to adapt to the oxidative stress for a short time. However, as time progresses, the anti-oxidative stress-associated genes cannot act against the continuous stress efficiently. Furthermore, the oxidative stress injures the cell, and the expression of genes may be interrupted, leading to the irreversible outcomes.

In conclusion, the present study demonstrated that the insertion site of AFM2658 was associated with anti-oxidative stress. TAIL-PCR was used to amplify the flanking sequences of RB and LB, and the sequences were blasted with the Af293 genome. The results revealed that the site was located between the IMP coding region and the HLH coding region, with the $\mathrm{RB}$ at the 5 ' site for $\sim 300 \mathrm{bp}$ of the HLH coding region and LB at the $5^{\prime}$ site for $\sim 100$ bp of the IMP-coding region, which may 
be either the 5'-untranslated region (UTR) or the intergenic region of the two genes. The 5'-UTR usually includes $\mathrm{m} 7 \mathrm{G}$, hairpin, uORF (upstream open frame) and internal ribosome entry site (IRES). Although the length of the 5'-UTR sequence of 100-200 bp is common, its length can vary between dozens and thousands, and is usually longer than the average length in genes regulating important processes, including cell growth (40). The HLH transcription factors confer regulation in several pathways in mammalian cells. The sequence replaced was aligned to a known 5'-UTR, based on the BLAST database (http://www.ba.itb.cnr.it/BIG/ Blast/utrblast.cgi). Notably, 16 bp af the sequence were identical to the 5'-UTR of the mRNA of Arabidopsis thaliana and Oryza sativa of the Japonica group (41). Thus, the identified site was more likely to be a 5'UTR, however, this was based on the site of transcription initiation, which can be confirmed using a 5'RACE experiment. Analyzing the sequence between the two coding regions provided no information about common promoters, including TATA box and CAAT box, however, the mRNA levels of HLH and IMP were altered, indicating that $\mathrm{H}_{2} \mathrm{O}_{2}$ sensitivity may shift following the changes in these two genes. Which structures are disrupted to result in the altered expression levels of these two genes remains to be elucidated and requires further investigation.

In conclusion, the present study used $\mathrm{H}_{2} \mathrm{O}_{2}$ as a model of oxidative stress to screen ATMT mutants exhibiting altered sensitivities to $\mathrm{H}_{2} \mathrm{O}_{2}$, and compared the AFM2658 strain with the wild-type strain in terms of colonial morphology, ROS levels and mRNA levels. It was revealed that the insertion site may be associated with $\mathrm{H}_{2} \mathrm{O}_{2}$ sensitivity, and the results provide a foundation for further investigations of the signaling pathways in fungi.

\section{Acknowledgements}

This study was supported by grants from the National Natural Science Foundation of China (grant nos. 81271802 and 81071334). The authors would like to the staff of Jilin University Mycology Research Center (Jilin, China).

\section{References}

1. Singh N and Paterson DL: Aspergillus infections in transplant recipients. Clin Microbiol Rev 18: 44-69, 2005.

2. Steinbach WJ, Marr KA, Anaissie EJ, Azie N, Quan SP, Meier-Kriesche HU, Apewokin S and Horn DL: Clinical epidemiology of 960 patients with invasive aspergillosis from the PATH Alliance registry. J Infect 65: 453-464, 2012.

3. Horn F, Heinekamp T, Kniemeyer O, Pollmächer J, Valiante V and Brakhage AA: Systems biology of fungal infection. Front Microbiol 3: 108, 2012

4. Nierman WC, Pain A, Anderson MJ, Wortman JR, Kim HS, Arroyo J, Berriman M, Abe K, Archer DB, Bermejo C, et al: Genomic sequence of the pathogenic and allergenic filamentous fungus Aspergillus fumigatus. Nature 438: 1151-1156, 2005.

5. Hartmann T, Sasse C, Schedler A, Hasenberg M, Gunzer M and Krappmann S: Shaping the fungal adaptome-stress responses of Aspergillus fumigatus. Int J Med Microbiol 301: 408-416, 2011.

6. Segal BH and Romani LR: Invasive aspergillosis in chronic granulomatous disease. Med Mycol 47 (Suppl 1): S282-S290, 2009.

7. Boyle KB, Stephens LR and Hawkins PT: Activation of the neutrophil NADPH oxidase by Aspergillus fumigatus. Ann NY Acad Sci 1273: 68-73, 2012
8. Lambou K, Lamarre C, Beau R, Dufour N and Latge JP: Functional analysis of the superoxide dismutase family in Aspergillus fumigatus. Mol Microbiol 75: 910-923, 2010.

9. Burns C, Geraghty R, Neville C, Murphy A, Kavanagh K and Doyle S: Identification, cloning and functional expression of three glutathione transferase genes from Aspergillus fumigatus. Fungal Genet Biol 42: 319-327, 2005.

10. Shibuya K, Paris S, Ando T, Nakayama H, Hatori T and Latge JP: Catalases of Aspergillus fumigatus and inflammation in aspergillosis. Nihon Ishinkin Gakkai Zasshi 47: 249-255, 2006.

11. Lamarre C, Ibrahim-Granet O, Du C, Calderone R and Latgé JP: Characterization of the SKN7 ortholog of Aspergillus fumigatus. Fungal Genet Biol 44: 682-690, 2007.

12. Lessing F, Kniemeyer O, Wozniok I, Loeffler J, Kurzai O, Haertl A and Brakhage AA: The Aspergillus fumigatus transcriptional regulator AfYapl represents the major regulator for defense against reactive oxygen intermediates but is dispensable for pathogenicity in an intranasal mouse infection model. Eukaryot Cell 6: 2290-2302, 2007.

13. Frealle E, Aliouat-Denis CM, Delhaes L, Hot D and Dei-Cas E: Transcriptomic insights into the oxidative response of stress-exposed Aspergillus fumigatus. Curr Pharm Des 19: 3713-3737, 2013.

14. Wiedner SD, Burnum KE, Pederson LM, Anderson LN, Fortuin S, Chauvigné-Hines LM, Shukla AK, Ansong C, Panisko EA, Smith RD and Wright AT: Multiplexed activity-based protein profiling of the human pathogen Aspergillus fumigatus reveals large functional changes upon exposure to human serum. J Biol Chem 287: 33447-33459, 2012.

15. Weld RJ, Plummer KM, Carpenter MA and Ridgway HJ: Approaches to functional genomics in filamentous fungi. Cell Res 16: 31-44, 2006.

16. Zhang Y, Li G, He D, Yu B, Yokoyama K and Wang L: Efficient insertional mutagenesis system for the dimorphic pathogenic fungus Sporothrix schenckii using Agrobacterium tumefaciens. J Microbiol Methods 84: 418-422, 2011.

17. Lazo GR, Stein PA and Ludwig RA: A DNA transformation-competent Arabidopsis genomic library in Agrobacterium. Biotechnology (NY) 9: 963-967, 1991.

18. Chen XL, Yang J and Peng YL: Large-scale insertional mutagenesis in Magnaporthe oryzae by Agrobacterium tumefaciens-mediated transformation. Methods Mol Biol 722: 213-224, 2011

19. Mullins ED, Chen X, Romaine P, Raina R, Geiser DM and Kang S: Agrobacterium-mediated transformation of Fusarium oxysporum: An efficient tool for insertional mutagenesis and gene transfer. Phytopathology 91: 173-180, 2001.

20. Michielse CB, Hooykaas PJ, van den Hondel CA and Ram AF: Agrobacterium-mediated transformation of the filamentous fungus Aspergillus awamori. Nat Protoc 3: 1671-1678, 2008.

21. Valiante V, Heinekamp T, Jain R, Härtl A and Brakhage AA: The mitogen-activated protein kinase MpkA of Aspergillus fumigatus regulates cell wall signaling and oxidative stress response. Fungal Genet Biol 45: 618-627, 2008.

22. Penttilä M, Nevalainen H, Rättö M, Salminen E and Knowles J: A versatile transformation system for the cellulolytic filamentous fungus Trichoderma reesei. Gene 61: 155-164, 1987.

23. Canton E, Espinel-Ingroff A and Pemán J: Trends in antifungal susceptibility testing using CLSI reference and commercial methods. Expert Rev Anti Infect Ther 7: 107-119, 2009.

24. Morano KA, Grant CM and Moye-Rowley WS: The response to heat shock and oxidative stress in Saccharomyces cerevisiae. Genetics 190: 1157-1195, 2012.

25. Sugui JA, Chang YC and Kwon-Chung KJ: Agrobacterium tumefaciens-mediated transformation of Aspergillus fumigatus: An efficient tool for insertional mutagenesis and targeted gene disruption. Appl Environ Microbiol 71: 1798-1802, 2005.

26. Brakhage AA, Bruns S, Thywissen A, Zipfel PF and Behnsen J: Interaction of phagocytes with filamentous fungi. Curr Opin Microbiol 13: 409-415, 2010

27. Moye-Rowley WS: Regulation of the transcriptional response to oxidative stress in fungi: Similarities and differences. Eukaryot Cell 2: 381-389, 2003

28. Nikolaou E, Agrafioti I, Stumpf M, Quinn J, Stansfield I and Brown AJ: Phylogenetic diversity of stress signalling pathways in fungi. BMC Evol Biol 9: 44, 2009.

29. Gasch AP, Spellman PT, Kao CM, Carmel-Harel O, Eisen MB, Storz G, Botstein D and Brown PO: Genomic expression programs in the response of yeast cells to environmental changes. Mol Biol Cell 11: 4241-4257, 2000 
30. Cuéllar-Cruz M, Briones-Martin-del-Campo M Cañas-Villamar I, Montalvo-Arredondo J, Riego-Ruiz L, Castaño I and De Las Peñas A: High resistance to oxidative stress in the fungal pathogen Candida glabrata is mediated by a single catalase, Ctalp and is controlled by the transcription factors Yap1p, Skn7p, Msn2p and Msn4p. Eukaryot Cell 7: 814-825, 2008.

31. Nicholls S, Straffon M, Enjalbert B, Nantel A, Macaskill S, Whiteway M and Brown AJ: Msn2- and Msn4-like transcription factors play no obvious roles in the stress responses of the fungal pathogen Candida albicans. Eukaryot Cell 3: 1111-1123, 2004.

32. Winzeler EA, Shoemaker DD, Astromoff A, Liang H, Anderson K, Andre B, Bangham R, Benito R, Boeke JD, Bussey $\mathrm{H}$, et al: Functional characterization of the $S$. cerevisiae genome by gene deletion and parallel analysis. Science 285: 901-906, 1999.

33. Michielse CB, Hooykaas PJ, van den Hondel CA and Ram AF: Agrobacterium-mediated transformation as a tool for functional genomics in fungi. Curr Genet 48: 1-17, 2005.

34. Temple MD, Perrone GG and Dawes IW: Complex cellular responses to reactive oxygen species. Trends Cell Biol 15: 319-326, 2005.
35. Yan L, Li M, Cao Y, Gao P, Wang Y and Jiang Y: The alternative oxidase of Candida albicans causes reduced fluconazole susceptibility. J Antimicrob Chemother 64: 764-773, 2009.

36. Kontoyiannis DP: Modulation of fluconazole sensitivity by the interaction of mitochondria and erg $3 p$ in Saccharomyces cere visiae. J Antimicrob Chemother 46: 191-197, 2000.

37. Xu XS, CY Z, QM L, HP D and W X: Study on the autofluorescence in fungi with laser scanning confocal microscope. Acta Laser Biology Sinica 11: 109-113, 2002.

38. Dreyer B, Morte A, Pérez-Gilabert M and Honrubia M Autofluorescence detection of arbuscular mycorrhizal fungal structures in palm roots: An underestimated experimental method. Mycol Res 110: 887-897, 2006

39. Zižka Z, Vêtrovský T and Gabriel J: Enhancement of autofluorescence of the brown-rot fungus Piptoporus betulinus by metal ions. Folia Microbiol (Praha) 55: 625-628, 2010.

40. Mignone F, Gissi C, Liuni S and Pesole G: Untranslated regions of mRNAs. Genome Biol 3: REVIEWS0004, 2002

41. Grillo G, Turi A, Licciulli F, Mignone F, Liuni S, Banfi S, Gennarino VA, Horner DS, Pavesi G, Picardi E and Pesole G: UTRdb and UTRsite (RELEASE 2010): A collection of sequences and regulatory motifs of the untranslated regions of eukaryotic mRNAs. Nucleic Acids Res 38 (Database Issue): D75-D80, 2010. 